which can be excluded on the basis of additional skin or limb abnormalities, such as in Roberts's pseudothalidomide syndrome or incontinentia pigmenti. The normal karyotype in our cases excluded chromosomal abnormalities and there was no evidence of a congenital rubella embryopathy.

When hypogonadism occurs in addition to microcephaly, mental retardation, and cataracts, only a small number of syndromes needs to be considered in the differential diagnosis. One is Smith-LemliOpitz syndrome, ${ }^{5}$ but cataracts in that syndrome are rare and, looking at table 2 , there are more differences than similarities. The other condition that needs excluding is the oculopalatocerebral syndrome, ${ }^{6}$ in which a cleft palate and a persistent hyperplastic primary vitreous with microphthalmia are cardinal features, but which are absent in Martsolf's syndrome.

Lowe's syndrome, ${ }^{7}$ which is $\mathrm{X}$ linked, was excluded by finding a normal amino acid pattern and galactosaemia was also biochemically excluded.

A number of other minor features were originally reported by both Martsolf $e t$ al $^{1}$ and Sanchez et al. ${ }^{2}$ These include brachycephaly, lax finger joints, talipes valgus, a pouting mouth, and maxillary retrusion with slight hirsutism, but these are difficult to evaluate. The facial features in the two sibs in this report are not distinct. Both are clearly microcephalic and have small jaws with slight hirsutism, but it remains uncertain whether facial dysmorphic features are useful in helping the clinician to establish the diagnosis.

It is of interest that one of the sibs had a cardiomyopathy and the other died from cardiac failure, although the exact nature of the lesion was not elucidated. The combination of cataracts, a cardiomyopathy, and nephronophthisis has been described in mitochondrial cytopathy. ${ }^{8}$ The child described in that report had typical features of a mitochondrial myopathy on muscle biopsy, whereas case 1 in our family had a muscle biopsy which was normal. Microcephaly in the neonatal period would also be very unusual in mitochondrial disease.

In summary, we report a brother and sister pair with features of Martsolf's syndrome to indicate its recessive nature and also to suggest that, in view of the presence of a cardiomyopathy in one sib and cardiac failure in the other sib, the spectrum is either larger than first anticipated or alternatively that the condition described in this paper is a separate genetically determined entity.

The authors thank Dr G McEnery, Whipps Cross Hospital, for his assistance in the preparation of this report.

References
1 Martsolf JT, Hunter AGW, Haworth JC. Severe mental
retardation, cataracts, short stature and primary hypogonadism
in two brothers. Am J Med Genet 1978;1:291-9.
2 Sanchez JM, Barreiro C, Freilij H. Two brothers with Martsolf's
syndrome. J Med Genet 1985;22:308-10.
3 Strisciuglo P, Costabile M, Esposito M, Di Maio S. Martsolf's
syndrome in a non-Jewish boy. J Med Genet 1988;25:267-9.
4 Hennekam RCM, van de Meeberg AG, van Doorne JM, et al.
Martsolf syndrome in a brother and sister: clinical features and
pattern of inheritance. Eur J Pediatr 1988;147:539-43.
Lowry RB. Variability in the Smith-Lemli-Opitz syndrome:
overlap with the Meckel syndrome. Am J Med Genet 1983;14:
$429-33$.
6 Frydman M, Kauschansky A, Leshem I, Savir H. Oculo-palato-
cerebral dwarfism: a new syndrome. Clin Genet 1985;27:414-9.
7 Smith DW, ed. Recognizable patterns of human malformation.
Philadelphia: Saunders, 1982:158.
8 Donaldson MDC, Warner AA, Trompeter RS, et al. Familial
juvenile nephronophthisis, Jeune's syndrome and associated
disorders. Arch Dis Child 1985;60:426-34.

Correspondence to Dr M Baraitser, Department of $\dot{\sigma}$ Clinical Genetics, The Hospitals for Sick Children, Great Ormond Street, London WC1N 3JH.

\title{
Dominant inheritance of Scheuermann's juvenile kyphosis
}

\author{
A FINDLAY*, A N CONNER†, AND J M CONNOR* \\ *Duncan Guthrie Institute of Medical Genetics, Yorkhill Hospitals, Glasgow; and †Department of \\ Orthopaedic Surgery, Royal Hospital for Sick Children, Glasgow.
}

SUMMARY We report a family in which Scheuermann's juvenile kyphosis is present in three successive generations with male to male transmission. This provides further evidence for autosomal dominant inheritance in at least some families with this condition.
Scheuermann's disease (MIM18144), or spinal osteochondrosis, although probably first recognised $\stackrel{0}{\leftarrow}$ by Stafford ${ }^{1}$ in 1832 , was described by Scheuermann in $1920 .^{2}$ It is a condition where there is an abnormal and fixed thoracic kyphosis of unknown aetiology that develops around the time of puberty. Associated with this physical deformity, Scheuermann ${ }^{2}$ found $\stackrel{\odot}{\mathbb{Q}}$ radiographical evidence of thoracic vertebral wedging 2 and irregularities of the growth plates of the affected 
vertebrae. A thoracic kyphosis is commonest with the summit usually in the area T6 to T11 and Scheuermann also noted a coexistent mild scoliosis in $75 \%$ of cases.

This is the most frequent cause of adolescent kyphosis with a population incidence of $0.4 \%$ to $8.3 \%$ depending upon whether the diagnosis was based, respectively, upon clinical or radiographical criteria, since not all are symptomatic.

\section{Case report}

A 14 year old boy (GLA7773) was referred for orthopaedic assessment as he had developed a round back deformity. The deformity was first noticed at the age of 13 and had been progressive. His father had been particularly concerned as both he and his own father had been similarly affected.

On examination, the boy was $170 \mathrm{~cm}$ tall, with a span of $170 \mathrm{~cm}$ and, in addition to a round back deformity, had a mild scoliosis to the left (fig 1). The deformity appeared relatively fixed with an exaggerated lumbar lordosis.

Radiographs confirmed that he had spinal

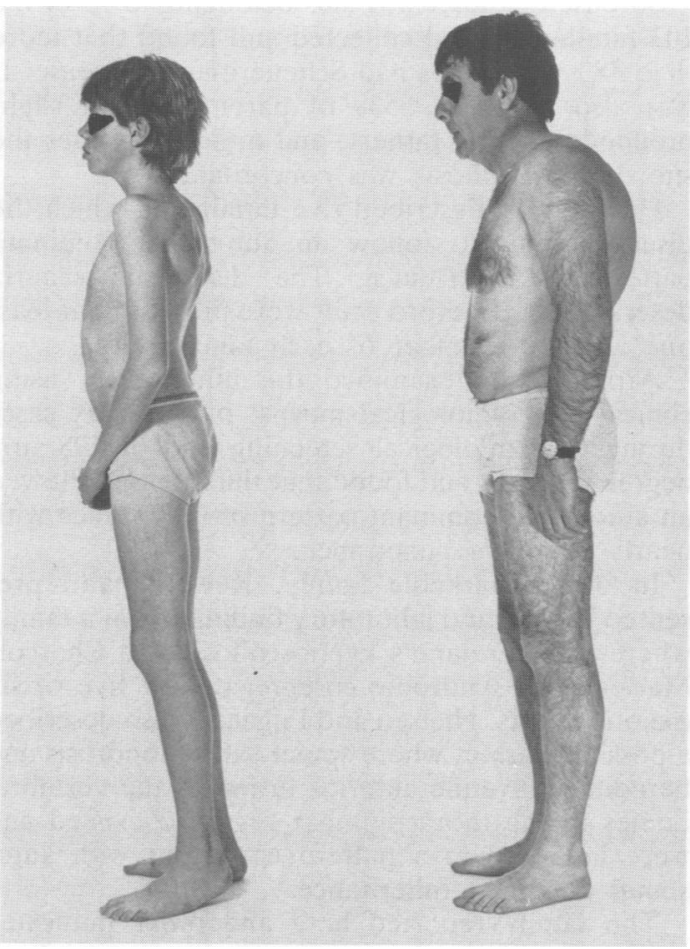

FIG 1 Photograph of index case and his father.

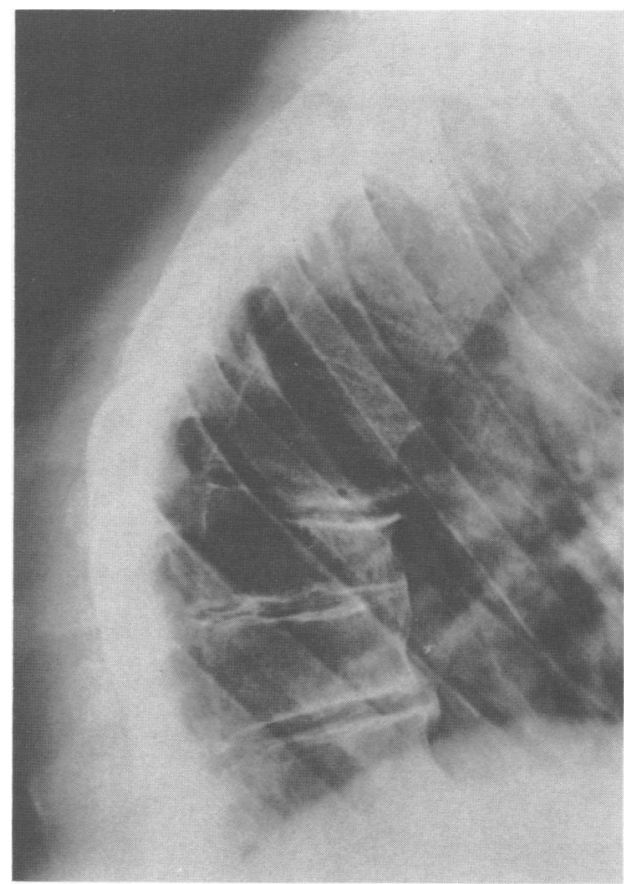

FIG 2 Lateral spine radiograph of index case.

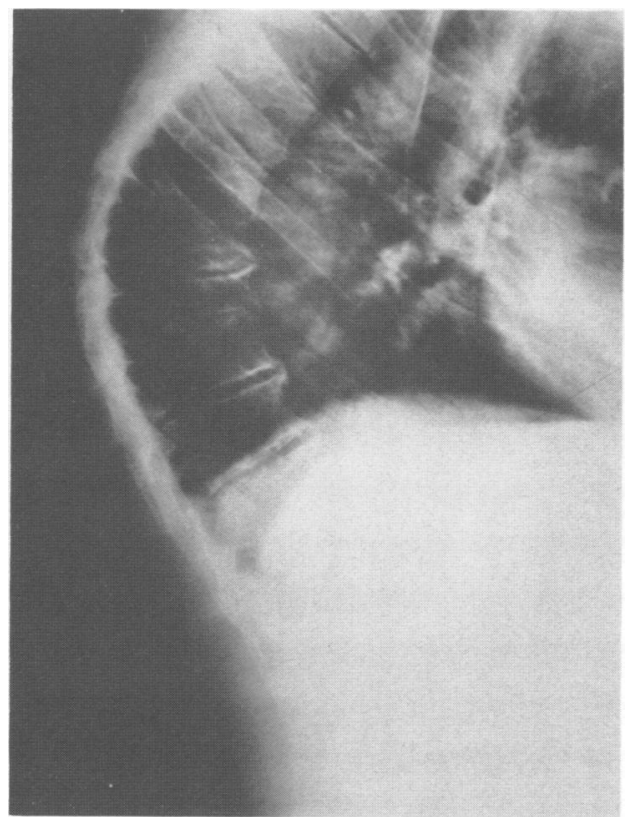

FIG 3 Lateral spine radiograph of father. 


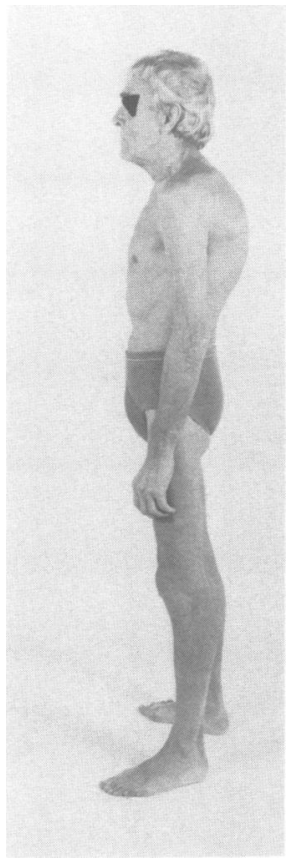

FIG 4 Photograph of grandfather.

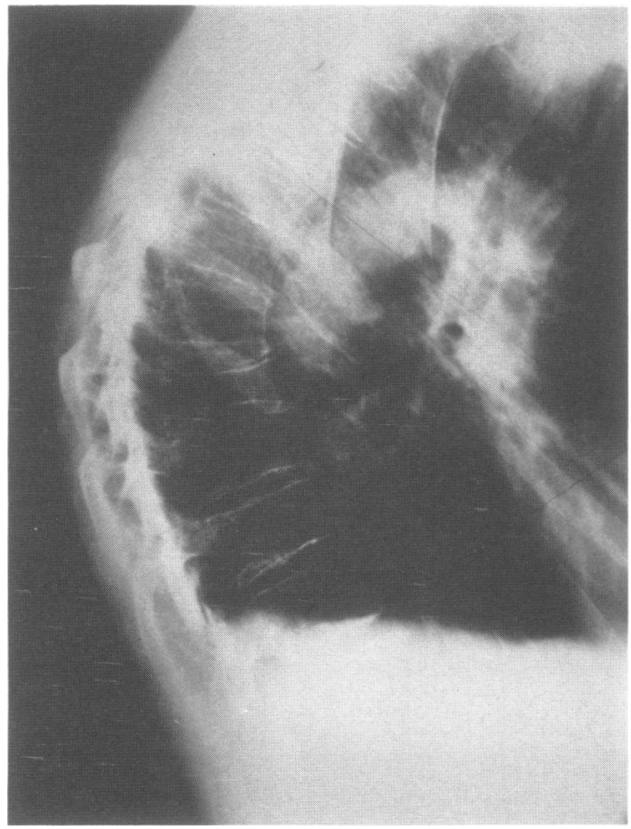

FIG 5 Radiograph of lateral spine of grandfather. osteochondrosis as there was irregularity of the $\stackrel{\overparen{\oplus}}{+}$ growth plates and wedging of the mid-thoracic $\vec{F}$ vertebrae producing a fixed kyphosis of $58^{\circ}$, which only corrected to $49^{\circ}$ on extension (fig 2). He had ac scoliosis from $\mathrm{T} 8$ to $\mathrm{L} 1$ to the left measuring $10^{\circ}$. $\frac{\bar{\sigma}}{\bar{c}}$ Correction of the kyphosis was attempted using $a_{\widetilde{\mathbb{Q}}}$ Milwaukee brace.

In the family history his father had developed aw round back deformity which had been static for $15 \vec{\circ}$ years despite no active treatment, and examination showed a similar but more severe deformity (fig 1). $\vec{\omega}$ A radiograph of his spine confirmed that he also had? Scheuermann's disease (fig 3).

The paternal grandfather had developed a similari round back deformity in his teens and a diagnosis of spinal osteochondrosis was confirmed both clinically: and radiologically (figs 4 and 5).

\section{Discussion}

Scheuermann's disease clearly shows familial clus- $-\stackrel{\Phi}{ }$ tering. Of seven sets of monozygotic twins collected $\vec{\oplus}$ by Scheuermann, ${ }^{2}$ six were clinically concordant,,. and Bjersand ${ }^{3}$ also described a concordant monozygotic twin pair.

Sorensen ${ }^{4}$ studied 151 sibs belonging to 79 of the 103 families he had collected and found that more than $48 \%$ of all sibs had Scheuermann's disease. It $\stackrel{\square}{\square}$ was also found in $65 \%$ of parents with a slight $\overrightarrow{\vec{P}}$ preponderance of fathers, and in $86 \%$ of cases the $\frac{0}{3}$ site of the kyphosis was concordant.

Halal et $a l^{5}$ described five families in which the disease seems to follow an autosomal dominant pattern of inheritance. The diagnostic criteria described by Bradford et at ${ }^{6}$ were present in at least ${ }^{0} \div$ one affected member of each family.

Arpad $\mathrm{et}^{\mathrm{al}} \mathrm{l}^{7}$ examined the inheritance, using clinical and radiological means, of 78 index cases $₹$ during epidemiological screening and of 198 first 0 degree relatives and found that the disease followed an autosomal dominant pattern of inheritance witho nearly complete penetrance.

In one remarkable family, Kewelramani ${ }^{8}$ pre- $/$ sented clinical and laboratory findings from a family $N$ where Scheuermann's kyphoscoliosis and CharcotMarie-Tooth syndrome cosegregated at five of six ${ }^{\omega}$ meiotic events. Nielsen and Pilgaard ${ }^{9}$ also described 2 a possible variant where spinal osteochondrosis and $\stackrel{\circ}{\complement}$ hereditary juvenile anterior fusion of the vertebral $\stackrel{\Phi}{\Phi}$ bodies in the thoracolumbar region coexisted and were inherited in a pattern consistent with autosomal dominant inheritance.

The family reported here and other published $\frac{\odot}{\odot}$ cases would support autosomal dominant inheri- $\stackrel{\mathbb{Q}}{\circ}$ tance in a substantial proportion of cases of Scheuer- -2 
mann's disease. Since in severe cases early diagnosis and treatment lead to a more favourable outcome, it is therefore important that the offspring of an affected person be examined carefully around puberty.

\section{References}

1 Stafford RA. The injuries, the diseases and distortions of the spine. London: Longmans, 1832.

2 Scheuermann HW. Kyfosis dorsalis juvenalis. Ugerkr Laeger 1920;82:385-93.

${ }^{3}$ Bjersand AJ. Juvenile kyphosis in identical twins. AJR 1980; 134:598-9.

4 Sorensen KH. Scheuermann's juvenile kyphosis: clinical appearances, radiography, aetiology and prognosis. Copenhagen: Munksgaard, 1964.
5 Halal F, Gledhill RB, Fraser FC. Dominant inheritance of Scheuermann's juvenile kyphosis. Am J Dis Child 1978;132: 1105-7.

6 Bradford DS, Moe JH, Montalvo FJ, Winter RB. J Bone Joint Surg (Am) 1976;56:740-58.

7 Arpad B, Sandor F, Gyorgy M, Gyorgy S, Erzsebet G. A Scheuermann-betegseg oroklodese. Magyar Traumatol 1986; 29:163-7.

8 Kewalramani LS. Scheuermann's kyphoscoliosis associated with Charcot-Marie-Tooth syndrome. Arch Phys Med Rehabil 1976;57:391-7.

${ }^{9}$ Nielsen OG, Pilgaard P. Two hereditary spinal diseases producing kyphosis during adolescence. Acta Paediatr Scand 1987;76:133-6.

Correspondence to Dr A Findlay, Duncan Guthrie Institute of Medical Genetics, Yorkhill, Glasgow G3 8SJ.

\title{
Prenatal diagnosis of the megacystis-microcolon-intestinal hypoperistalsis syndrome
}

\author{
I D YOUNG*, P A McKEEVER†, L A BROWN†, AND G D LANG \\ Departments of Child Health*, Pathologyt, and Obstetrics and Gynaecology $\neq$, Leicester Royal Infirmary, \\ Leicester.
}

SUMMARY The ultrasonographic and necropsy findings in a male fetus with the megacystismicrocolon-intestinal hypoperistalsis syndrome are reported. The presence of vacuolation and degeneration in smooth muscle of bowel and bladder wall supports a previous suggestion that the macroscopic findings in this syndrome are the consequence of an underlying visceral myopathy. The unusual degree of severity of the findings in this fetus may explain the marked skewing of the sex ratio observed in affected liveborn infants.

The megacystis-microcolon-intestinal hypoperistalsis (MMIH) syndrome is a rare condition in which the underlying pathogenesis is poorly understood. Affected sibs have been reported on five occasions ${ }^{1-5}$ and there have been two reports of parental consanguinity, ${ }^{46}$ so that autosomal recessive inheritance is highly probable. However, a review of published reports indicates a striking excess of affected females over males. We now describe the prenatal and necropsy findings in an affected male fetus which offer some insight into the likely explanation for this apparent skewing of the sex ratio.

Received for publication 27 September 1988

Revised version accepted for publication 2 December 1988.

\section{Case report}

The fetus was the product of the third pregnancy of healthy, unrelated parents. Their first child was a healthy female. The next pregnancy resulted in the delivery of a male infant who died at the age of four hours as a consequence of multiple abnormalities, which were believed to include urethral atresia and possible intestinal atresia. Necropsy was not undertaken.

Because of the absence of a clear diagnosis in this baby, the parents requested that their third pregnancy be monitored by ultrasonography. At 18 weeks a section through the fetal abdomen showed a markedly distended bladder with ascites and oligohydramnios (fig 1). Termination of pregnancy was requested. The male fetus was noted to have a grossly distended abdomen with no other obvious external anomalies. At necropsy the small and large bowel were malrotated with the caecum and appendix in the right hypochondrium. The colon was very narrow in diameter (fig 2) with a patent lumen. Small strands of mesentery were wound around the caecum, appendix, and duodenum. The liver and gallbladder were normal and the presence of gross ascites was confirmed. Both kidneys were small and dysplastic. The ureters were mildly dilated at their distal ends and the bladder was grossly distended (fig 3 ). Normal male genitalia were present. 